\title{
Avaliação social da palatalização de /t, d/ em Sergipe
}

\author{
Social evaluation of the palatalization of $/ t, d /$ in Sergipe
}

\author{
Cristiane Conceição de Santana Ribeiro * \\ Universidade Federal de Sergipe \\ São Cristóvão, Sergipe, Brasil
}

\author{
Thaís Regina de Andrade Corrêa** \\ Universidade Federal de Sergipe \\ São Cristóvão, Sergipe, Brasil
}

Resumo: O estudo das atitudes linguísticas mostra múltiplos aspectos linguísticos inerentes a uma comunidade. A percepção de um fenômeno linguístico depende do julgamento do ouvinte, que correlaciona fatores sociais a traços sociolinguísticos. A avaliação social das variáveis costuma ser inferida por meio de padrões de uso sendo ela um fator decisivo na constituição da identidade linguística dos falantes (FREITAG, 2016). Este foi um estudo piloto desenvolvido com o objetivo de analisar as percepções e atitudes linguísticas de informantes do interior e da capital de Sergipe diante da palatalização regressiva e progressiva. Adotamos uma abordagem indireta utilizando a técnica de matched guise (LAMBERT et. al. 1966). Foram criados 48 estímulos com contextos de palatalização regressiva, progressiva e frases distratoras. Realizamos uma testagem inicial de naturalizada a um contexto de fala e criamos os estímulos pareados utilizando 12 estímulos oito deles com as variáveis sob análise e quatro distratores. O instrumento segue o modelo proposto por Oushiro (2015) e participaram 58 juízes do estado de Sergipe, residentes no interior e capital. Os resultados deste teste apontaram para uma diferença na percepção dos informantes do interior em relação aos da capital diante da palatalização de /t,d/, tanto antecedida quanto posposta ao /i/. Esse resultado pode estar atrelado à questão do estigma e do prestígio social que cada uma dessas variantes apresenta na comunidade em questão.

Palavras-chave: Testes de atitudes, abordagem indireta, avaliação social, palatalização.

Abstract: The study of linguistic attitudes shows multiple linguistic aspects inherent in a community. The perception of a linguistic phenomenon depends on the judgment of the listener, who correlates social factors with sociolinguistic traits. The social evaluation of variables is usually inferred through use patterns and is a decisive factor in the constitution of the linguistic identity of the speakers (FREITAG, 2016). This was a pilot study developed with the objective of analyzing the perceptions and linguistic attitudes of informants from the interior and the capital of Sergipe in the face of the regressive and progressive palatalization. We adopt an indirect approach using the matched guise technique (LAMBERT et. al. 1966). The 48 stimuli were created in contexts of regressive, progressive palatalization and phrases distracting. The sample is 12 stimuli, eight of them with the variables under analysis and their variants and four distractors. We developed a questionnaire following Oushiro (2015), composed of eight questions both quantitative and qualitative. The attitudes tests were applied to 58 listeners from the state of Sergipe, most of them being held at the Federal University of Sergipe by listeners living in the interior and capital. The results of this test pointed to a difference in the perception of the informants from the interior to those of the capital in the face of the palatalization of $/ \mathrm{t}, \mathrm{d} /$, both before and after the $/ \mathrm{i} /$. This result may be tied to the question of the stigma and social prestige that these variants present in the community in question.

Keywords: Attitude tests, indirect approach, social evaluation, palatalization.

* Mestranda em Letras da Universidade Federal de Sergipe. E-mail: criscc.santan@gmail.com ** Mestranda em Letras da Universidade Federal de Sergipe. E-mail: thayss_andrade@hotmail.com 


\section{INTRODUÇÃO}

A Sociolinguística de base variacionista parte da premissa de que o sistema linguístico é heterogêneo, possível de ser sistematizado mediante descrição de regras categóricas e variáveis, as quais possibilitam usos alternativos de formas linguísticas expressando o mesmo valor de verdade. A escolha entre o uso de uma variante linguística em detrimento de outra não acontece de modo aleatório; o processo de variação é influenciado pelos condicionamentos linguísticos, sociais, estilísticos, pragmáticos. Embora, no Brasil, muitos estudos sociolinguísticos já tenham sido desenvolvidos em relação à produção de usos linguísticos, seguindo as preconizações dos estudos seminais do campo, Oushiro (2015) e Freitag (2016) sugerem que, para uma abordagem mais abrangente da variação e mudança, é importante incluir o modo como diferentes variantes linguísticas são ouvidas e avaliadas pelos membros que constituem uma dada comunidade de fala.

As abordagens de produção e percepção sociolinguísticas têm especificidade e objetivo distintos, no entanto, elas podem ser adotadas juntamente para uma análise mais ampla e rica de uma determinada variante, visto que uma complementa a outra, conforme apresenta Freitag (2017), enquanto os estudos de usos linguísticos têm natureza observacional, descreve os padrões de recorrência de uma variante e têm por objetivo explicar como as formas linguísticas e significados sociais se vinculam e por que. Os estudos de percepção têm natureza experimental, procura mostrar os julgamentos dos falantes em relação a uma variante e tentam verificar como as formas linguísticas e os seus significados sociais afetam a percepção do falante e o seu processamento linguístico.

No campo da sociolinguística, o estudo das atitudes linguísticas mostra múltiplos aspectos linguísticos inerentes a uma comunidade. A percepção de um fenômeno linguístico depende do julgamento do ouvinte, que correlaciona fatores sociais a traços sociolinguísticos. A avaliação social das variáveis costuma ser inferida por meio de padrões de uso, sendo ela, um fator decisivo na constituição da identidade linguística dos falantes (FREITAG, 2016).

Segundo Labov (2008), considerando a avaliação social e o nível de consciência dos falantes, existem três tipos de níveis de consciência: os indicadores que são traços linguísticos que não exibem nenhum padrão de alternância estilística e que tem pouca força avaliativa na sociedade; os marcadores são traços linguísticos que exibem estratificação tanto estilística quanto social, estão abaixo do nível de consciência, e por isso suscitará respostas regulares em testes avaliativos; os estereótipos que são traços fortemente marcados dentro da sociedade e propensos a julgamentos muito mais rigorosos e taxativos.

Dentre esses três níveis, trabalhamos com o estereótipo, que se caracteriza como crenças, julgamentos ou sistemas conceituais, segundo Leite (2011, p.96):

O estereótipo reforça a autoestima, definida como a avaliação que o sujeito faz de sua própria persona. Em poucas palavras, pode-se dizer que: se negativo, o estereótipo se vincula a questões relacionadas ao preconceito e à tensão entre grupos sociais; se positivo, relaciona-se às questões de identidade social. 
As avaliações positivas ou negativas em relação às atitudes linguísticas não se dão pelas características inerentes à linguagem, mas sim a algum aspecto linguístico associado aos valores sociais que cada variante carrega dentro da comunidade (LEITE, 2011).

Um modelo de percepções sociolinguísticas e dos significados sociais de variantes deve dar conta não apenas das inferências realizadas pelos ouvintes, mas também daquelas que se dão diferentemente ou que não se realizam, e por quê (OUSHIRO, 2015, p. 320).

Em um estudo realizado no estado de Sergipe, por FREITAG et alii (2016), utilizando uma abordagem direta (reações explícitas) para saber qual atitudes dos falantes em relação a palatalização progressiva (/oitu/ > /oit $\int \mathrm{u} /, /$ muitu/ > /muit $\int \mathrm{u} /$, /biscoitu/ > / biscoit $\int \mathrm{u} /$ ), em uma comunidade de práticas aracajuana, foi percebido nas respostas que a avaliação social para este fenômeno por parte dos informantes é tida como desprestigiada socialmente. Vejamos o excerto (1), retirado da amostra da comunidade de práticas desse estudo, o Atheneu Sergipense (FREITAG et alii, 2016, p. 141).

(1)Doc: (...) na língua portuguesa a questão da variação linguística que você pode falar que uma mesma palavra tem várias pronuncias, mas que é o mesmo significado por exemplo... quando você fala biscoito você vai entender 0 que é que eu estou pedindo a você e se eu falar biscoitfo você vai entender o que eu to pedindo a você mas essa diferença que tem entre uma palavra e outra essa diferença sonora o que você acha? Se você no seu grupo da escola falasse assim?

ELE-F: ah seria zuação porque as pessoas quando você fala uma palavra errada elas começam a zuar

Doc: ai se eu começasse a falar aqui oitfenta carros se eu tivesse oitfo reais

$\boldsymbol{E L E - F : ~ a c a b a m ~ z u a n d o ~ v i r a ~ m o t i v o ~ d e ~ z u a c ̧ a ̃ o ~ q u a n d o ~ f a l a ~ v o c e ̂ ~ a l g u m a ~ p a l a v r a ~ q u e ~ e l e s ~ n a ̃ o ~ e s t a ̃ o ~ a c o s t u m a d o s ~}$ a ouvir palavras diferentes principalmente se você era do interior e veio para cidade e você começa a falar quer queira quer não você sempre pega um pouco do sotaque do local de onde você mora então quando você começa a usar aquele sotaque do interior aqui você acaba sendo discriminado então você tem que se adaptar ao máximo ao modo como as pessoas naquele novo determinado local. (Ele-F, F, E, A, 320)

Outro estudo a respeito de tal variável no Estado de Sergipe foi realizado por Andrade, Evangelista e Santana (2016), nesse estudo, as autoras adotaram uma abordagem direta em relação ao uso da variante sob análise utilizando um questionário fonético fonológico que continha perguntas que proporcionavam respostas possíveis de serem palatalizadas, por exemplo, uma das perguntas foi "Por qual outro nome podemos chamar bolacha?" e as respostas possivelmente dadas seriam "biscoi/t/o" (em que ocorreria a

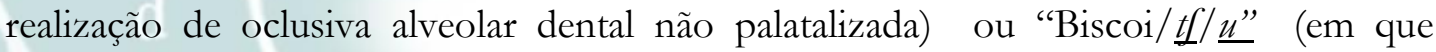
ocorreria a realização de oclusiva alveolar dental palatalizada em ambiente progressivo. A finalidade desse trabalho foi verificar se a palatalização de /t/ e /d/ em ambiente progressivo era considerado como um traço linguístico estigmatizado socialmente na cidade de São Cristóvão. Os resultados mostraram que essa variante foi mais frequente na fala de pessoas pouco escolarizadas, residentes da zona rural e mais idosas.

Os resultados desse estudo se assemelham aos que foram apresentados por Souza Neto (2008) em que o perfil dos informantes aracajuanos que mais fizeram uso de tal variante foi pessoas acima de 50 anos e pouco escolarizadas.

Esses resultados (SOUZA NETO, 2008, MOTA, 2003; 2008; FREITAG, 2015; 2016; ANDRADE; EVANGELISTA; SANTANA, 2016, dentre outros) dão indícios que 
a palatalização de /t/ e /d/ em ambiente progressivo está associada à menor escolarização, às pessoas mais idosas e às regiões não urbanas, fatores que podem configurar um estereótipo não prestigiado por parte das pessoas mais jovens, com nível alto de escolarizada e da zona urbana.

Segundo Labov ([1972] 2008) uma problemática a respeito da avaliação social feita somente por meio de reações explícitas leva os ouvintes a fazer julgamentos superficiais de observação usando, muitas das vezes, estereótipos rudes em relação a uma dada variante linguística, a utilização somente desse tipo de abordagem pode fazer com que o ouvinte não reflita sobre suas opiniões pessoais e sim reproduza o que já é disseminado. Já a utilização da abordagem indireta (reações subjetivas) utilizando a técnica de matched guises (estímulos pareados), desenvolvida Lambert et al. (1960) troux6 um novo aparato metodológico para avaliar as reações sociais de forma inconsciente a respeito das atitudes linguísticas dos falantes de forma encoberta.

Com base nesse modelo metodológico, procuramos, neste estudo, descrever a percepção e as atitudes linguísticas de informantes do interior e da capital de Sergipe, em relação ao processo fonológico de palatalização de /t, d/ regressiva e progressiva, a exemplo de: / oitu/ > / oit $\int \mathrm{u} / \mathrm{e} / \mathrm{s} \varepsilon t \mathrm{i} />/ \mathrm{s} \varepsilon \mathrm{t} \int \mathrm{i} /$, respectivamente. Este foi um estudo piloto desenvolvido com o objetivo de identificar se há atitudes positivas ou negativas em relação aos fenômenos analisados e qual deles foi o mais estigmatizado e prestigiado pelos informantes.

\section{A ABORDAGEM SUBJETIVA DA AVALIAÇÃO SOCIAL}

Um dos primeiros estudos que utilizou a técnica de matched guises para avaliar as reações subjetivas dos falantes foi o de Lambert et al. (1966). O objetivo de utilizar esse modelo metodológico foi identificar as principais diferenças na caracterização dos falantes que possam ser atribuídas a diferentes atitudes empregadas ao idioma utilizado e não necessariamente ao falante. A finalidade deste estudo foi analisar as reações dos ouvintes montrealenses de fala francesa e de fala inglesa quanto ao inglês e ao francês na cidade de Montreal (Canadá). Os pesquisadores usaram a técnica de matched guises que consistia em gravar quatro falantes bilíngues (que falavam inglês e francês canadense), que leram um mesmo texto nas duas línguas o que acabou originando oito leituras. Para realizar os testes de percepção, os autores adicionaram mais duas gravações como distratoras junto as oito que foram gravadas. As gravações foram apresentadas a 130 ouvintes, estudantes universitários de duas universidades de Montreal, sendo 65 anglófonos e 65 francófonos. Os resultados deste estudo mostraram que a influência de estereótipos sobre o inglês e o francês na comunidade montielense, como um todo, afetam os falantes de ambas as línguas.

Campbell-Kibler (2010) também desenvolveu um estudo utilizando essa técnica de falsos pares. Este estudo objetivou analisar as percepções e atitudes sobre a variável (ING), verificar como as pistas linguísticas funcionam em diferentes estilos de fala e o impacto da variável analisada sobre as percepções sociais dos ouvintes falantes apresentados como: professores, candidatos políticos ou outros profissionais experientes. Os resultados deste estudo mostram que diferentes pistas fornecidas aos ouvintes sobre 
o falante fazem com que se tenha uma percepção diferente. Segundo a autora, o estilo na linguagem, como em outros domínios, refere-se a "uma maneira de fazer algo" que ganha o seu significado de uma história particular, vinculada por essa história a lugares, pessoas, situações e posições emocionais, entre outras coisas. Uma dada prática linguística pode unicamente ser ligada a um único estilo ou pode ser incorporada a vários estilos diferentes.

Oushiro (2015) fez uso desse aparato metodológico para realizar uma pesquisa sobre percepção e atitudes linguísticas na cidade de São Paulo, cujo objetivo central da sua pesquisa consistiu em analisar as inter-relações entre a expressão de identidades sociais por meio de usos linguísticos e a possível influência dos significados sociais desses usos em processos de variação e mudança linguística na comunidade paulistana. Mas a fim de melhor compreender os mecanismos subjacentes à associação de certos significados sociais ao emprego de diferentes formas linguísticas, a autora examina, no capítulo $10 \mathrm{da}$ sua tese de doutorado, as percepções sobre as variantes de (-r), com base na técnica de estímulos pareados (Lambert et al., 1960).

Os resultados, deste estudo, mostraram que o principal significado das variantes se refere a identidades geográficas (capital $v$ s. interior; centro $v$ s. periferia), e tais significados se estendem para o status relativo dos falantes. Conforme apontam as análises, o retroflexo é julgado mais negativamente em traços que se referem ao status dos falantes e mais positivamente em características associadas às dimensões de solidariedade e dinamismo. Segundo a autora, esses resultados estão de acordo com estudos já realizados, que verificaram que línguas, variedades e variantes favorecidas pelas classes menos privilegiadas são percebidas mais negativamente quanto a atributos de status e valorizadas quanto a traços de solidariedade.

Leite (2004) desenvolveu um estudo utilizando a abordagem de reações explícitas em que buscou identificar e analisar as atitudes linguísticas de alguns estudantes, migrantes da cidade de São José do Rio Preto (SP) em direção à cidade de Campinas (SP), em relação à alteração do /r/ em posição de coda. O objetivo desse estudo foi comprovar que o fenômeno em análise impulsiona uma estigmatização do dialeto típico do interior de São Paulo.

Os resultados desta análise mostraram, por meio das atitudes linguísticas dos falantes que participaram da pesquisa, que a variante retroflexa é estereotipada diante do grupo de estudantes que "optaram" por outras variantes: a alveolar e vogal colorida, uma vez que as avaliam como uma forma prestigiosa em detrimento da retroflexa, variante típica da cidade de São José do Rio Preto. Os estudantes também julgaram que as variantes alveolares e a vogal colorida representam uma pronúncia característica do dialeto de Campinas. A autora diz que o resultado não se trata de um caso de mudança linguística que esteja em progresso. Mas sim de um determinado grupo de falantes diante de uma situação específica em que avaliam positivamente uma forma prestigiosa e a realizam, ou ao menos se esforçam para realizá-la.

\section{METODOLOGIA}

Adotamos a abordagem subjetiva utilizando a técnica de matched guise, desenvolvida por Lambert et al. (1966), para elaborar os testes de atitudes. O primeiro passo 
metodológico foi criar os falsos pares; nessa etapa, quatro participantes que se disponibilizaram a colaborar com a pesquisa. Os voluntários foram dois homens e duas mulheres, estudantes da Universidade Federal de Sergipe, todos eram sergipanos. Numa cabine acústica, pedimos que os participantes lessem 48 frases cada um, com instruções para a realização: 24 delas com a variante oclusiva e outras 24 com variante palatalizada. Finalizado o processo de gravação das sentenças, o trecho que seria usado como estímulo foi manipulado e foram selecionados 12 áudios para compor o teste, foram oito áudios que continham as variáveis sob análise e quatro distratores.

O instrumento de coleta do teste segue o modelo proposto por Oushiro (2015), com 8 questões, com respostas de três formas: por escala gradual de cinco (indo de "com certeza não a com certeza”), por respostas de múltipla escolha e marcação de caixa.

Participaram do teste 58 juízes, residentes no estado de Sergipe. A maior parte dos testes foi realizada na Universidade Federal de Sergipe por participantes residentes do interior e capital. Também aplicamos nos municípios de São Cristóvão e Lagarto.

\section{RESULTADOS}

Nesta seção, apresentamos os resultados em duas partes, visto que não podemos atribuir à mesma valoração às variantes em análise. A realização variável da palatalização de /t/ e /d/, a depender do ambiente em que ocorre, se progressivo ou regressivo, leva a julgamentos sociais diferenciados.

\subsection{A PALATALIZAÇÃO EM AMBIENTE PROGRESSIVO}

O fenômeno da palatalização das oclusivas dentais / t/ e /d/ consiste no levantamento da língua em direção à parte posterior do palato duro levando a ampliação da zona articulatória para a produção de uma consoante ocasionando assim uma mudança fonética (CÂMARA JR. 1977). A consoante que exibe a propriedade secundária de palatalização apresenta um efeito auditivo de sequência de consoante seguida ou precedida de /i/. Esse fenômeno geralmente ocorre quando uma consoante é seguida de vogais anteriores /I, e, $\varepsilon /$ (orais ou nasais) ou antecedida pela semivogal /i/ Cristófaro (2008).

Em palavras como /oitenta/, /muito/, /doida/, /biscoito/ dentre outras que tenham a semivogal / i/ antes dos fonemas /t/ e /d/ é possível ocorrer variação fonológica, ou seja, transformam-se em oclusivas alveolares dentais palatalizadas e nesse processo o uso dos alofones $/ \mathrm{t} \int / \mathrm{e} / \mathrm{d} 3 /$, fazendo com que as palavras tenham outra representação fonológica como em /oit $\int e n t a /, /$ muit $\int u /$, /biscoit $\int u /, / \operatorname{doid} 3 a /$, embora haja alteração no som a compreensão da palavra continua sendo a mesma. No entanto, não podemos dizer que o julgamento social dessa variante seja o mesmo. Como já abordado na seção da introdução, Freitag et alii (2016) mostram que numa comunidade de práticas escolar da capital de Sergipe, a palatalização progressiva é tida como desprestigiada socialmente, o que significa que tal variante é vista como um estereotipo negativo.

Para realização do teste de percepção da variante palatal em ambiente progressivo, utilizamos as seguintes frases para julgamento: 
(3) quatro mais quatro é igual a oito (estímulo auditivo não palatalizado)

(4) quatro mais quatro é igual a oitfu (estímulo auditivo palatalizado).

Conforme as instruções do questionário aplicado, os falantes “juízes” julgavam 1 para com certeza não; 2 para acho que não; 3 para não sei; 4 para acho que sim ; 5 para com certeza. No gráfico 1, observamos que os juízes consideram que a pessoa que faz uso variante palatalizada não é formal, na caixa em cor cinza onde a linha mais forte está na resposta de número 2, que significa "acho que não". Já na caixa cor vermelha, que representa a variante não palatalizada, as respostas se concentram mais no nível 4, que significa "acho que sim", ou seja, uma forma falada em ambientes formais.

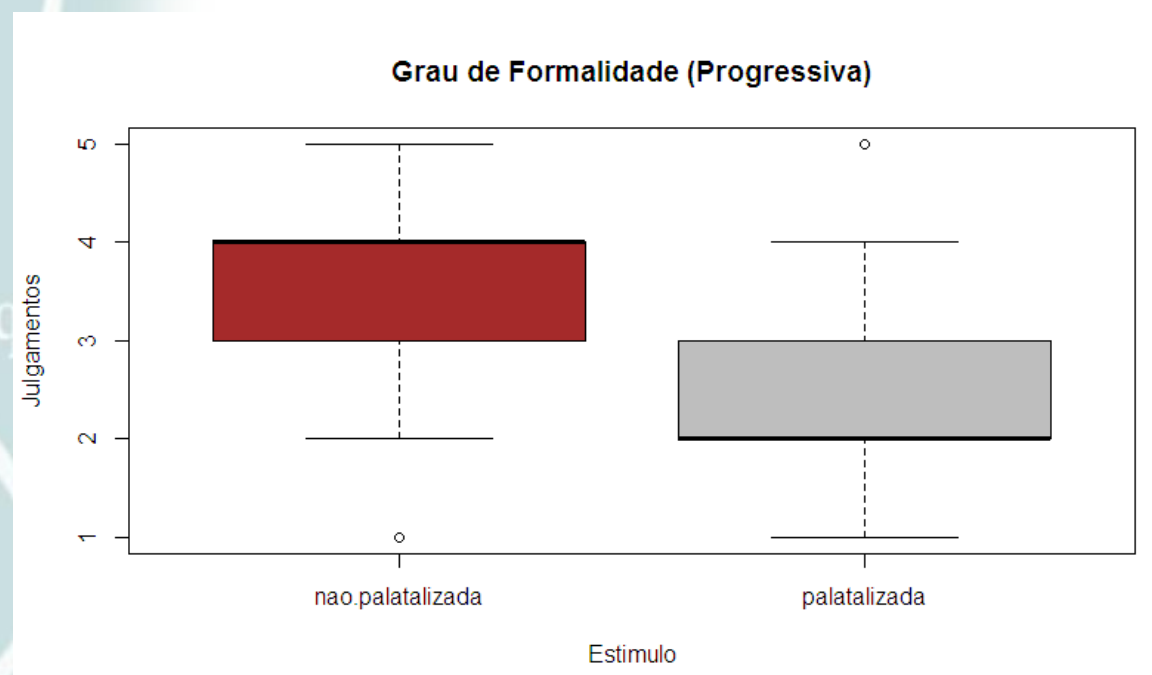

Gráfico 1: Julgamento das variantes palatal e não palatal sobre a formalidade

Diante da pergunta se esta pessoa é escolarizada, conforme é apresentado no gráfico 2), os participantes tiveram um julgamento neutro em relação à variante palatalizada, como mostra a caixa de cor cinza, ou seja, não houve um posiconamente, visto que o maior número de respostas ficou no nível 3, que significa "não sei”, o que sugere que, diante dessa variante, a maior parte dos juizes não se posicionou. Já a caixa de cor vermelha sugere um julgamento positivo e um posicionamento em relação à variante não palatalizada, pois as respostas se concentraram no número 4, mostrando, assim, que os juízes atribuem valores sociais diferenciados no que se refere à escolaridade relacionada a dada variante. 


\section{Revista

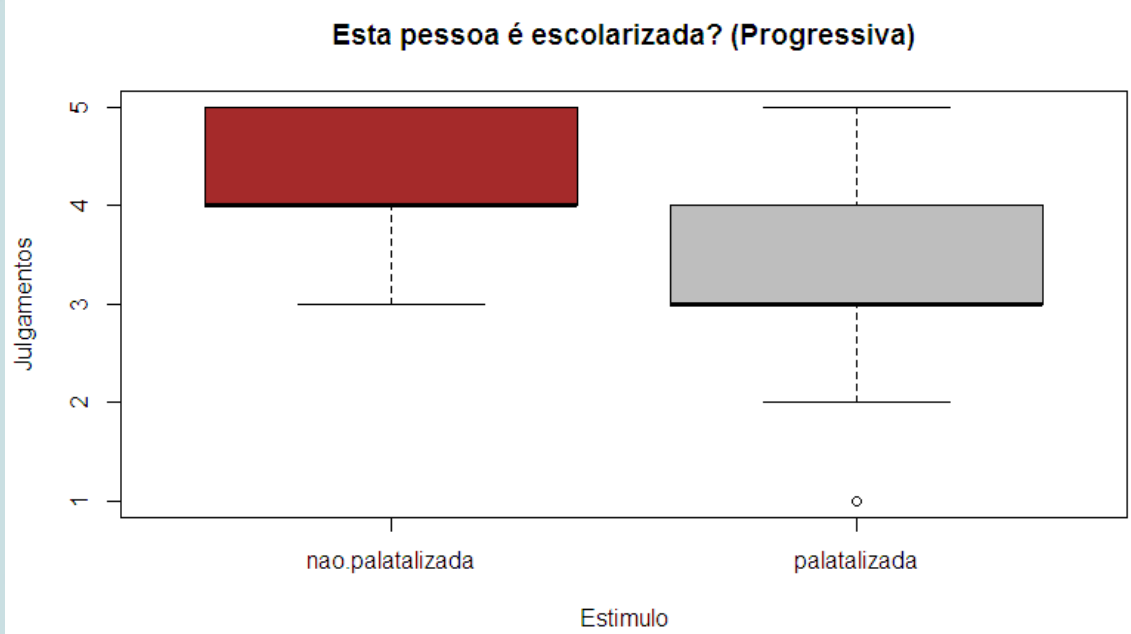

Gráfico 2: Julgamento das variantes palatal e não palatal sobre a escolarização

No gráfico 3, apresentamos os resultados das respostas dos juízes em relação à variável resposta "falar bem"; há diferença nas respostas em relação à palatalização em ambiente progressivo: enquanto a variante não palatalizada concentrou suas respostas no nível 4 "acho que sim", (caixa vermelha), a variante palatalizada concentrou suas respostas no número 3 "não sei", (caixa cinza), ou seja, pode-se inferir que os juízes tiveram mais certeza em dizer que quem não palataliza neste ambiente fala melhor do que quem faz uso da variante palatal.

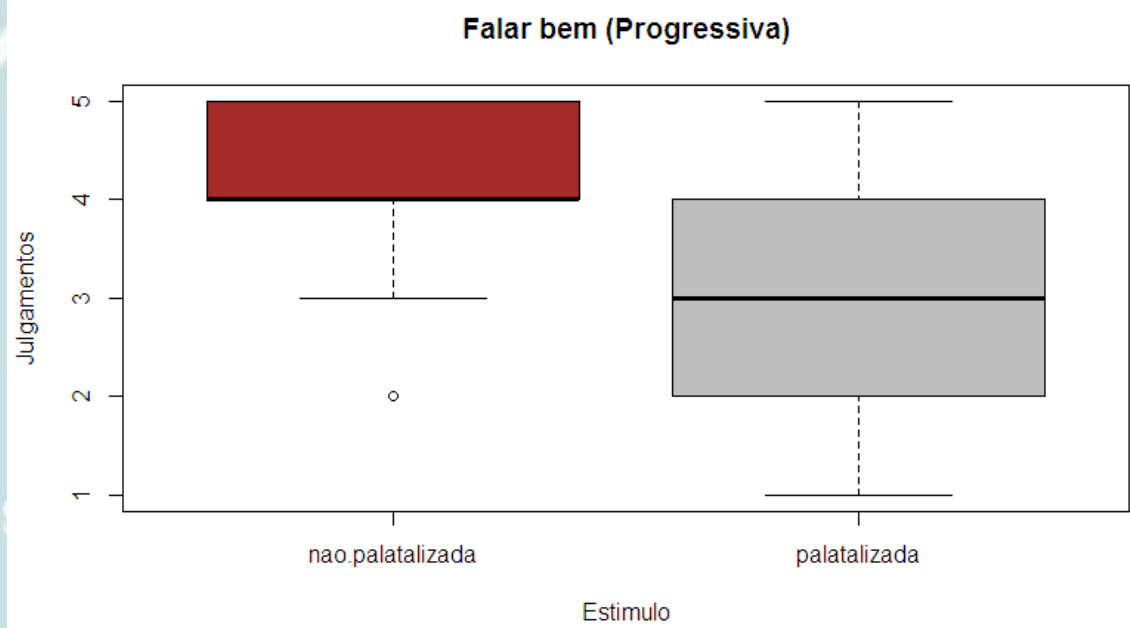

Gráfico 3: Julgamento das variantes palatal e não palatal sobre a falar bem 
O gráfico 4 mostra os resultados dos juízes para a pergunta "esta pessoa fala bonito?" Em relação à variante não palatal da qual se tem a maior recorrência de uso na camunidade de fala sergipana segundo Freitag (2016), a maior parte dos juíszes elegeram, na escala, o nível 4 "acho que sim". Já a variante palatalizada não foi avaliada positivamente, os ouvintes escolheram o nível 2 da escala, que se refere à resposta "acho que não". Estes resultados reforçam que a palatalização progressiva não é avaliada positivamente, na amostra composta por universitários sergipanos.

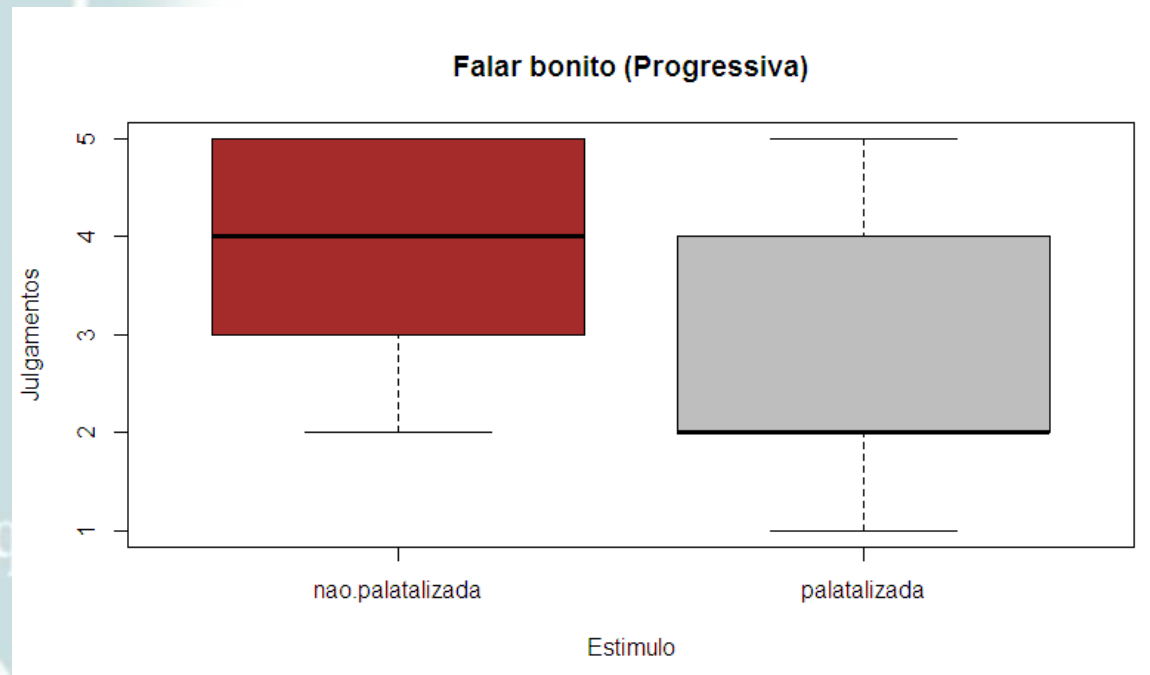

Gráfico 4: Julgamento das variantes palatal e não palatal sobre a falar bonito

A pergunta "onde esta pessoa deve morar?" apresentava opções de resposta de múltipla escolha. Os participantes juízes ouviram o estímulo auditivo e julgaram se a pessoa que estava falando era do interior ou da capital. Conforme o gráfico 5 , a variante não palatalizada apresenta distribuição mais equilibrada na avaliação dos juízes, embora a tendência das respostas seja de que quem não palataliza pode morar mais na capital do que no interior, a diferença foi sutil se comparada com a variante palatalizada, que por sua vez, foi avaliada como de um falante do interior. Este resultado corrobora com os estudos de testes explícitos já feitos em Sergipe (cf. FREITAG, 2016). 

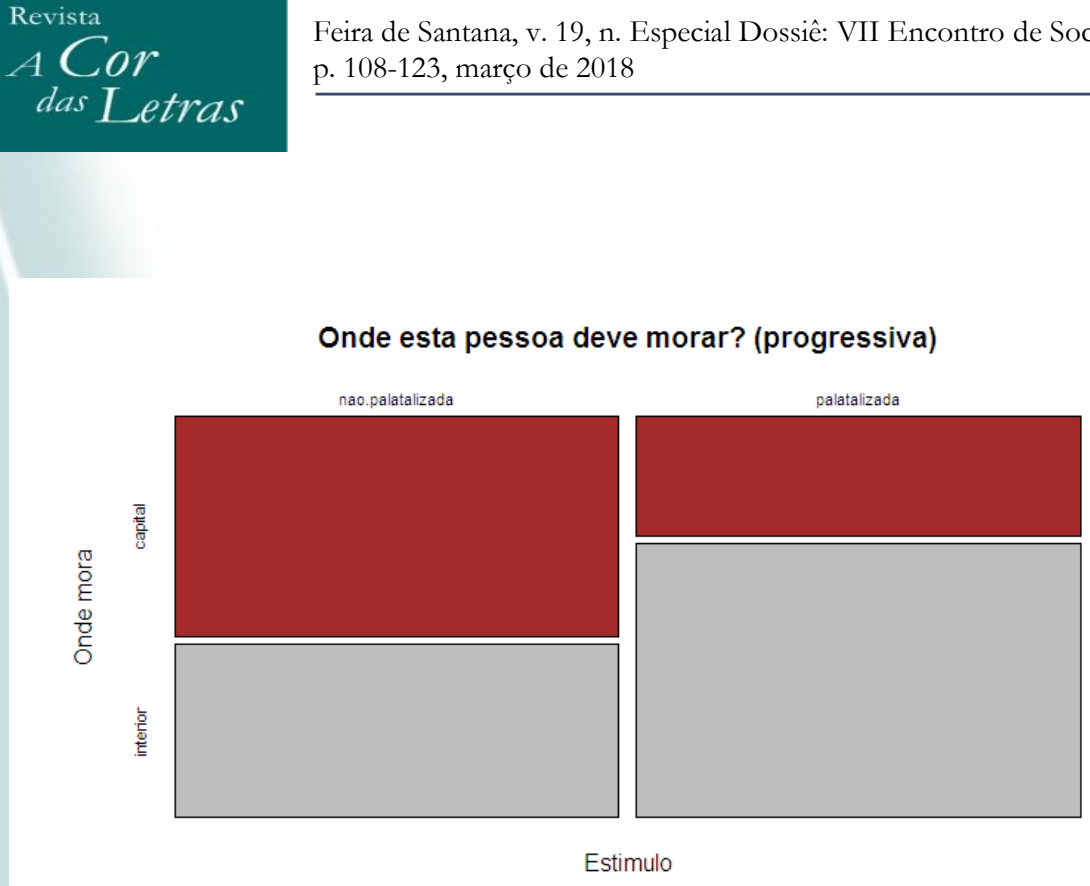

Gráfico 5: Julgamento das variantes palatal e não palatal em relação a localidade.

Embora a variante não palatalizada seja mais recorrente e considerada padrão dentro da comunidade a palatalização apresenta traços identitários em comunidades de Sergipe. Neste caso podemos concluir que assim como o retroflexo, como mostra Oushiro (2015), e a alteração do r em coda, como mostra Leite (2004), a palatalização em ambiente progressivo também carrega traços de identidade social e avaliação negativa.

\subsection{A PALATALIZAÇÃO EM AMBIENTE REGRESSIVO}

$\mathrm{Na}$ palatalização de ambiente regressivo também há uma mudança fonética dos fones $/ \mathrm{t} / \mathrm{e} / \mathrm{d} /$ para os alofones $/ \mathrm{t} \mathrm{f} / \mathrm{e} / \mathrm{d} 3 /$ em que uma mesma palavra pode ter duas representações fonológicas como em den/t/e $\sim \mathrm{den} / \mathrm{t} / \mathrm{e}, \mathrm{me} / \mathrm{d} / \mathrm{ico} \sim \mathrm{me} / \mathrm{d} 3 /$ ico dentre outras palavras que tenham as consoantes $/ \mathrm{t} / \mathrm{e} / \mathrm{d} /$ seguida de vogais anteriores /I, e, ع/. Assim como é atribuído julgamento de valor diante da palatalização em ambiente progressivo, o mesmo acontece com o ambiente regressivo. No entanto, a essa variante é dada valorações sociais de prestígio, ela é vista como sendo um estereotipo positivo.

Para realização do teste de percepção da variante palatal em ambiente regressivo, utilizamos as seguintes frases para julgamento:

(5) "três mais quatro é igual a se/t/e" (estímulo auditivo não palatalizado)

(6) "três mais quatro é igual a se/tf/e" (estímulo auditivo palatalizado)

Em relação ao fenômeno de palatalização regressiva, o ambiente condicionador, a vogal /i/, muda de lugar, sendo posposta à oclusiva /d/ e /t/. De acordo com Souza Neto (2014), Freitag e Santos (2016), e Souza (2016), do ponto de vista do uso, o estudo da variação na realização de /d/ e /t/, em Sergipe, aponta para uma mudança incipiente, e está mais adiantada na capital do que no interior. O gráfico 6 mostra equilíbrio na escolha do nível da escala, os juízes escolheram o ponto neutro 3 referente à formalidade para a 


\section{Revista

palatalização e para a não palatalização. É importante ressaltar que, embora as respostas tenham se concentrado no nível 3, "não sei", houve respostas desde o nível 2 até o nível 4 e seus julgamentos se assemelham.

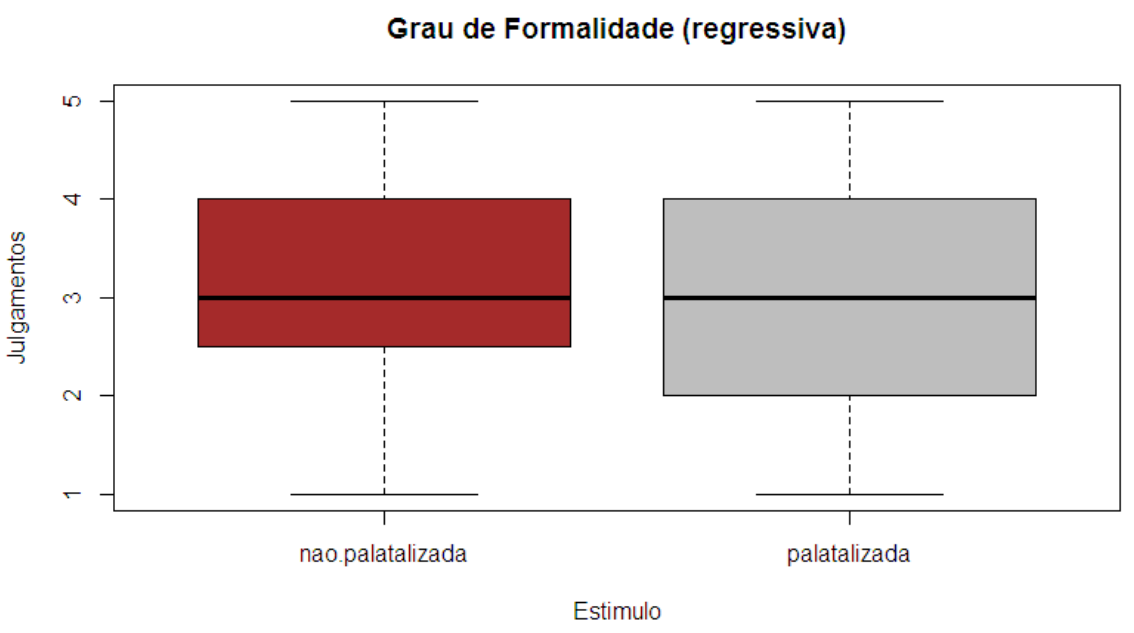

Gráfico 6: Julgamento das variantes palatal e não palatal sobre a formalidade

Para a variável resposta escolaridade, os participantes julgaram como escolarizada a pessoa que usou as duas variantes, mas deve-se levar em consideração que a variante palatalizada foi julgada mais positivamente, chegando até o nível 5, "com certeza sim", do que a não palatalizada, que não alcançou o nível mais alto.

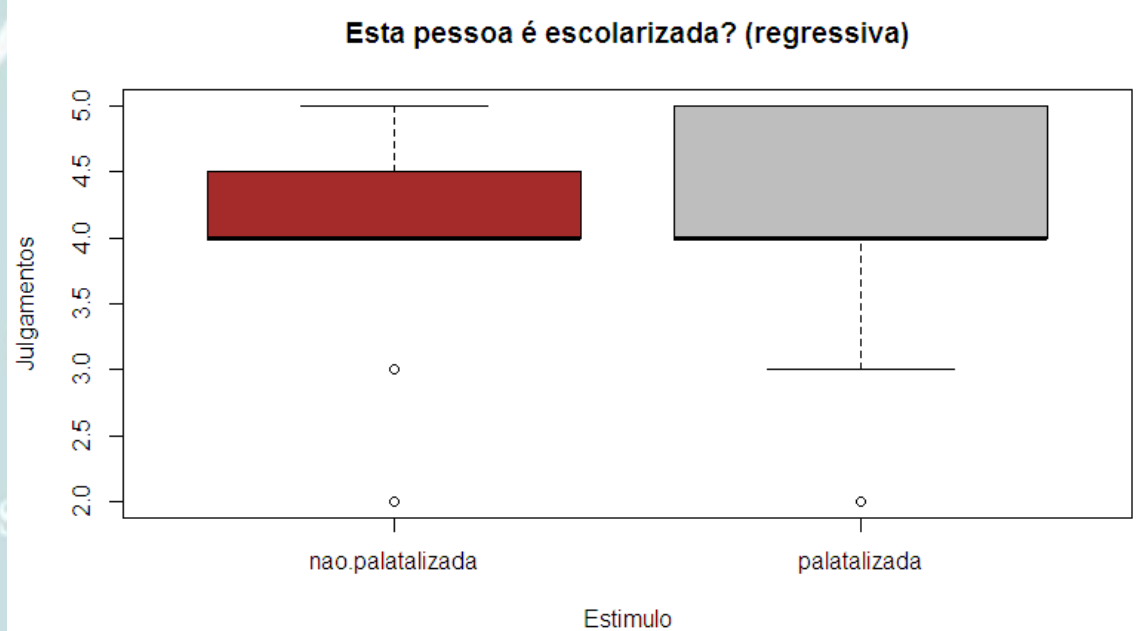

Gráfico 7: Julgamento das variantes palatal e não palatal sobre a escolarização 
Quando perguntado se "essa pessoa fala bem?", a variante palatalizada também foi avaliada mais positivamente do que a não palatalizada. Embora a média das respostas tenha se concentrado no nível, 4 "acho que sim", a palatalização regressiva gerou mais respostas no nível 5 "com certeza sim”. Esse resultado mostra o prestígio desta variante nesta comunidade e pode dar suporte aos estudos de mudança do ponto de vista da produção.

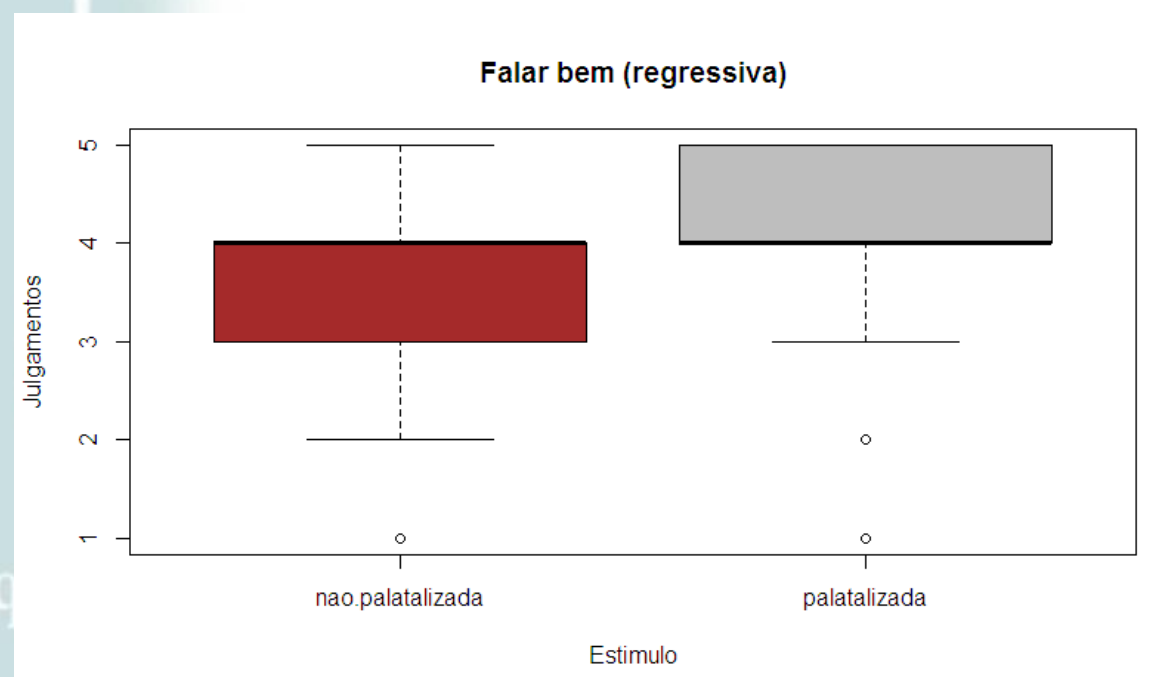

Gráfico 8: Julgamento das variantes palatal e não palatal sobre a falar bem

Os resultados referentes à variável "falar bonito" apresentaram concentração de julgamentos no nível 4, tanto para a forma palatalizada, quanto para a forma não palatalizada, mas é importante observar que no eixo da média, a linha mais escura, a concentração de respostas varia do nível 3 ao 4 (caixa vermelha) para a palatalizada, e do nível 3 ao 5 (caixa cinza) para a não palatalizada. Este resultado também reforça a valorização que os juízes dão para o fenômeno de palatalização regressiva. 

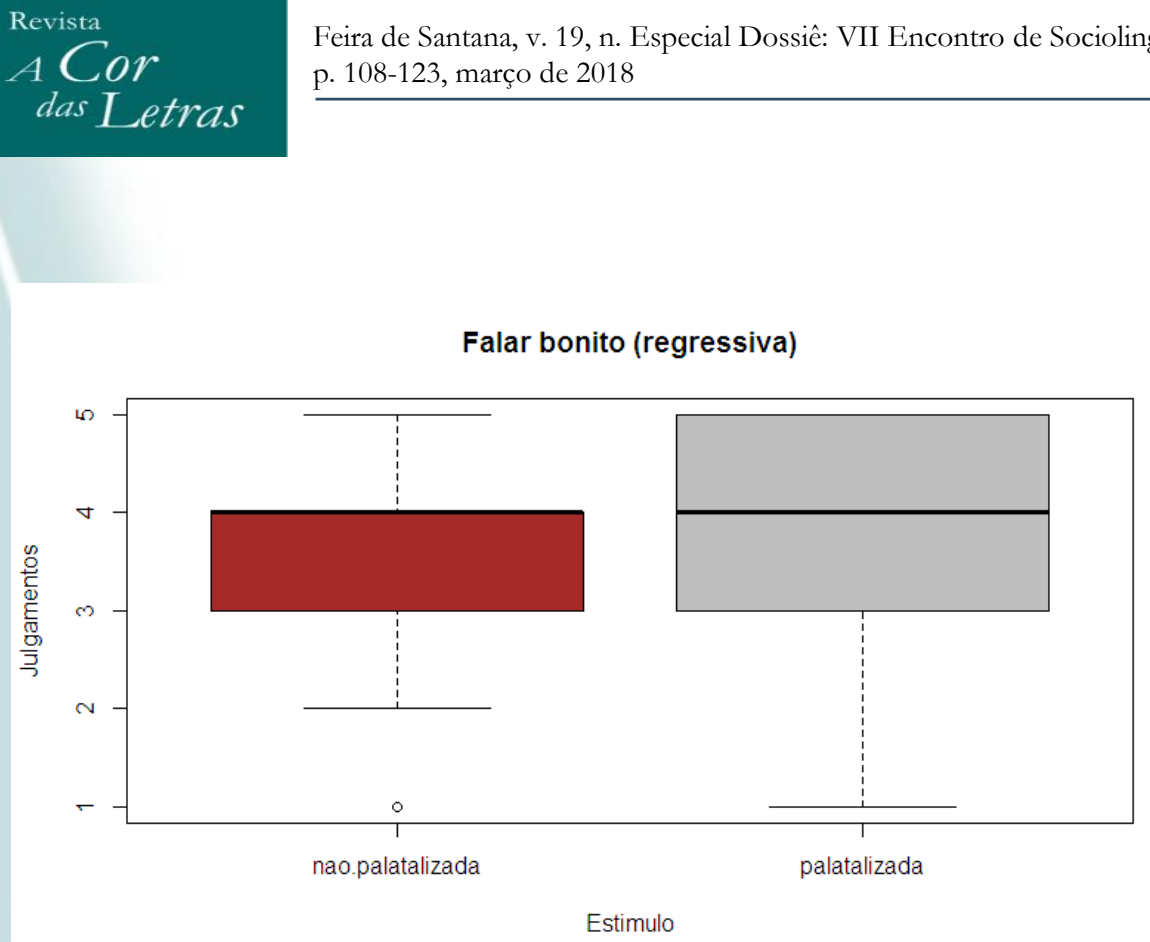

Gráfico 9: Julgamento das variantes palatal e não palatal sobre a falar bonito

O gráfico referente à pergunta "onde essa pessoa deve morar?" mostra que os participantes julgaram como da capital a fala da pessoa que fez uso da variante palatalizada. Podemos perceber que a variante não palatalizada foi julgada indiferentemente, podendo ser tanto da capital quanto do interior, já as respostas para a variante palatalizada apresentam uma diferença polarizada. Poucos participantes julgaram essa forma como sendo do interior, a maioria indicou a capital como local de residência de quem faz uso da variante palatal regressiva. Esse resultado é mais um indício de valorização desse fenômeno e corrobora com resultados de uso em estudos de produção, como é apresentado em Souza (2016), em que a os informantes da capital favoreceram o maior uso da variante palatalizada, enquanto os informantes do interior mostraram-se pouco favoráveis a tal variante.

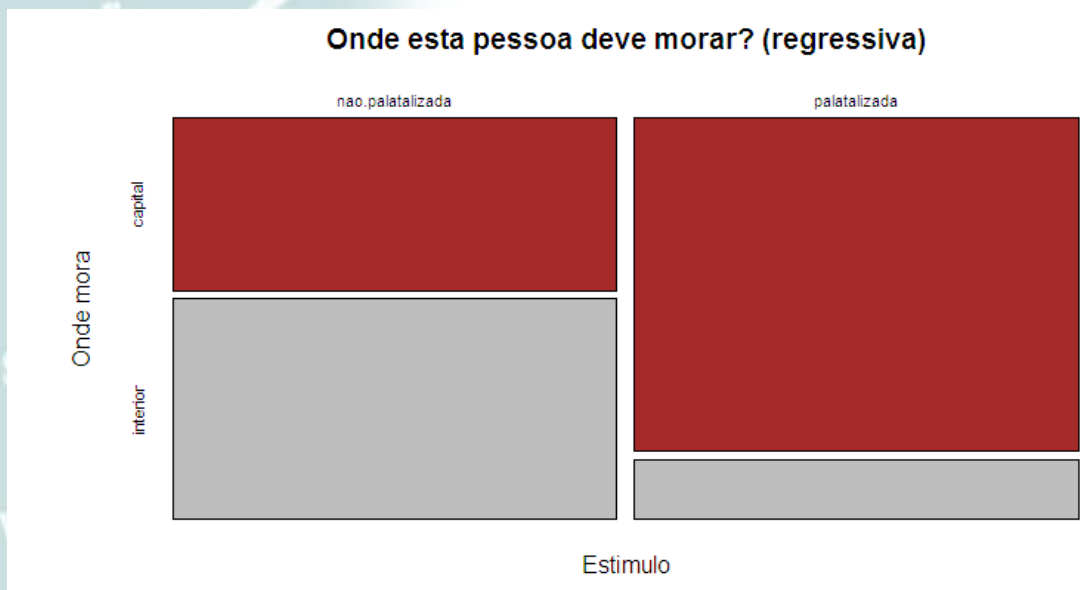

Gráfico 10: Julgamento das variantes palatal e não palatal em relação a localidade 


\section{CONSIDERAÇÕES FINAIS}

Os resultados deste teste sugerem que o fenômeno da palatalização seja em ambiente progressivo ou regressivo são altamente avaliados socialmente por se caracterizar como um estereotipo social. Podemos ver, conforme foi apresentado nos resultados, que os ouvintes julgaram negativamente a variante palatal em ambiente progressivo / oit $\int \mathrm{u}$ /, caracterizando essa forma como sendo típica de pessoas do interior, de baixa escolarização, que falam informalmente, que não falam bem e não falam bonito. Já a variante palatalizada em ambiente regressivo, /set $\int i$, foi avaliada positivamente na comunidade, caracterizando-se como fala bonita, de pessoas escolarizadas e formais, principalmente residentes na capital e que falam bem. Em relação às oclusivas dentais, variantes em que as que não ocorreu a palatalização / oitu/ e /seti/, os julgamentos foram próximos da neutralidade, não sendo nem positivos nem negativos. Os resultados dessa análise sugerem uma diferença na percepção dos informantes na fala de quem é do interior e de quem é da capital diante da palatalização de /t, d/, tanto antecedida quanto posposta ao $/ \mathrm{i} /$.

Esse resultado pode estar atrelado à questão do estigma e do prestígio social que essas variantes apresentam na comunidade em questão, visto que uma variante pode ser estigmatizada em uma comunidade e não ser em outra, o mesmo pode acontecer com a variante de prestígio que pode não ser prestigiada em outra comunidade. Estudos sobre palatalização em ambiente progressivo que foram feitos em Sergipe, como os de Souza Neto (2014), Souza (2016), Freitag $(2015,2016)$ e Freitag et al (2016), mostram que uma a uma mesma variante linguística pode ser atribuído valorações sociais diferentes a depender da comunidade na qual ela está inserida.

\section{REFERÊNCIAS}

ANDRADE, T. R. C.; EVANGELISTA, F. R. S.; SANTANA, R. R.. A palatalização das Oclusivas Dentais /t/ e /d/ Antecedidas por Glide em São Cristóvão/SE. Web-Revista SOCIODIALETO, v. 6, p. 622-637, 2016.

CAMPBELL-KIBLER, K. The effect of speaker information on attitudes toward (ING). Journal of Language and Social Psychology, vol. 29, n. 2, 214-223, 2010.

FREITAG, R. M. K. Uso, crença e atitudes na variação na primeira pessoa do plural no Português Brasileiro. D.E.L.T.A., vol. 32. n. 4, p. 889-917, 2016.

FREITAG, Raquel Meister Ko. Socio-stylistic aspects of linguistic variation: schooling and monitoring effects. Acta Scientiarum. Language and Culture, v. 37, n. 2, p. 127-136, 2015.

FREITAG, R. M. K.; SANTOS, A. O. Percepção e atitudes linguísticas em relação às africadas pós-alveolares em Sergipe. In: Norma da Silva Lopes, Silvana Silva de Farias Araújo, Raquel Meister Ko. Freitag. (Org.). A Fala Nordestina: entre a sociolinguística e a dialetologia. São Paulo: Blucher, 2016, p. 109-122. 
FREITAG, R. M. K. et alii. Avaliação e variação linguística: estereótipos, marcadores e indicadores em uma comunidade escolar. In: FREITAG, R. M. K.; SEVERO, C. G., GORSKI, E. M. (org). Sociolinguistica e politica linguística: olhares contemporâneos. São Paulo: Blücher, 2016, p. 141-160.

FREITAG, R. M. K. et al. Como os brasileiros acham que falam? Percepções sociolinguísticas de universitários do Sul e do Nordeste. TODAS AS LETRAS, v. 18, n. 2, p. 64-84, 2016.

LABOV, W. Padrões sociolinguísticos. São Paulo: Editora Parábola, 2008 [1972].

LAMBERT, W. W.; LAMBERT, W. E. Psicologia social. Rio de Janeiro: Zahar Editores, 1966.

LEITE, C. M. B. Atitudes linguísticas: a variante retroflexa em foco. Dissertação de Mestrado. Campinas: Unicamp, 2004. 138f.

LEITE, C. M. B. Estereótipos sociais e suas implicações para os estudos sociolinguísticos. Estudos da Lingua(gem), v. 9, p. 71-90, 2011.

MOTA, J. A. A variação diafásica no português do Brasil. Revista de Letras, v. 24, n.1/2, p. 70-74, 2003.

MOTA, J. A. Como fala o nordestino: a variação fônica nos dados do Projeto Atlas Lingüístico do Brasil. In: Maria Célia Lima-Hernandes; Maria João Marçalo; Guaraciaba Micheletti; Vilma Lia de Rossi Martin. (Org.). A língua portuguesa no mundo. São Paulo: FFLCH-USP, 2008, v. 1

OUSHIRO, L. Identidade na pluralidade: avaliação, produção e percepção linguística na cidade de São Paulo. Tese. Universidade de São Paulo, 2015.

SOUZA NETO, Antônio Felix de. Realizações dos fonemas / t/ e / d/ em Aracaju - SE. São Cristóvão: Editora UFS, 2014.

SOUZA, G. G. A. Palatalização de oclusivas alveolares em Sergipe. Dissertação (Mestrado em Letras). Universidade Federal de Sergipe, 2016. 